\title{
Proposições para a formação de aconselhadores em HIV/Aids
}

\author{
I ${ }^{1}$ Wedna Cristina Marinho Galindo, ${ }^{2}$ Ana Lúcia Francisco, \\ ${ }^{3}$ Luís Felipe Rios I
}

Resumo: Problematiza-se a formação de aconselhadores em HIV/Aids, exigência do Ministério da Saúde, para que profissionais de saúde desenvolvam essa prática junto ao usuário que busca testagem anti-HIV. Abordar a formação é estratégico para qualificar sua prática na direção de construção de respostas mais eficazes e efetivas à Aids. Análises de manuais do ministério e de entrevistas com aconselhadores, realizadas em pesquisa de tese (em andamento), subsidiam a discussão. Destacam-se das análises dos manuais uma concepção de subjetividade-identidade, como uma marca inexorável definida pelas práticas sexuais do usuário, e tendência prescritiva e diretiva nas recomendaçôes aos profissionais. Das análises de entrevistas, destacam-se os modos de aconselhar identificados - instrução e relação. Esses achados se somam às reflexões em torno do aconselhamento - tratado como dispositivo em saúde e como produção não material no contexto das reflexões sobre o mundo do trabalho nas sociedades capitalistas. Sugere-se que o aconselhamento tende a ser capturado por uma perspectiva mercadológica, pela íntima associação entre racionalidade científica e econômica, no campo da saúde. Esse arranjo é sustentado pela ainda hegemônica ideologia biomédica nas práticas em saúde. Para escapar dessa direção, sugere-se posicionamento crítico do aconselhador na execução de seu trabalho, evitando postura diretiva e protocolar. $\mathrm{O}$ aconselhamento-relação apresenta-se como modo de aconselhar alternativo, pelo uso de tecnologias leves, relações horizontalizadas, respeito às singularidades e o protagonismo do usuário nos cuidados de si. São apresentadas, finalmente, proposições (princípios e conteúdos) para a realização de processos formativos na direção do aconselhamento-relação.

> Palavras-chave: aconselhamento; pessoal de saúde; educação em saúde.

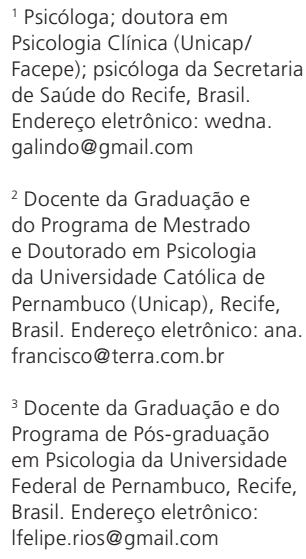

1 Psicóloga; doutora em

Psicologia Clínica (Unicap/ Facepe); psicóloga da Secretaria de Saúde do Recife, Brasil. Endereço eletrônico: wedna. galindo@gmail.com

${ }^{2}$ Docente da Graduação e do Programa de Mestrado e Doutorado em Psicologia da Universidade Católica de Pernambuco (Unicap), Recife, Brasil. Endereço eletrônico: ana. francisco@terra.com.br

${ }^{3}$ Docente da Graduação e do Programa de Pós-graduação em Psicologia da Universidade Federal de Pernambuco, Recife, Brasil. Endereço eletrônico: Ifelipe.rios@gmail.com 


\section{Introdução}

O aconselhamento é um dispositivo em saúde coletiva preconizado pelo Ministério da Saúde (MS) para acompanhar exame anti-HIV, disponibilizado à população brasileira em unidades de saúde. No final da década de 1990, o MS instituiu os Centros de Testagem e Aconselhamento em DST/Aids (CTA) como unidades de referência para diagnóstico e prevenção de DST/Aids (BRASIL, 1999; 1998; 1993). Políticas de expansão têm ampliado, mais recentemente, as possibilidades de testagem e aconselhamento para além dos CTA (BRASIL, 2005). O aconselhamento é ancorado em três tarefas - informar, avaliar riscos e apoiar emocionalmente o usuário -, devendo ser exercido por profissional de saúde capacitado para tal.

Vários aspectos têm sido colocados em debate sobre o trabalho em saúde na sociedade contemporânea. Associa-se o trabalho em saúde ao quadro geral dos serviços; argumenta-se que ele não é produtivo, pois de acordo com teóricos de inspiração marxista, o produto por excelência da sociedade capitalista é a mais-valia, não gerada pelo trabalho em saúde, ao menos quando exercido por profissionais liberais, sem vínculo empregatício (PIRES, 2008; TRAVERSOYÉPEZ, 2008). O aconselhamento em HIV/Aids, como prática de cuidado no campo da saúde, está sendo considerado como trabalho não-material, cuja produção e consumo ocorrem no mesmo momento em que é executado, diferente, portanto, da produção material, típica da indústria (MERHY, 2007).

Embora o debate sobre o trabalho em saúde envolva tantos aspectos, são apresentadas aqui reflexões sobre a prática do aconselhamento em HIV-Aids no Sistema Único de Saúde (SUS). O material exposto é parte de pesquisa de tese sobre aconselhamento em HIV/Aids e consiste em proposições para a formação de aconselhadores. Para tanto, o material trabalhado neste artigo apoia-se em dois produtos da referida pesquisa: análise de manuais do MS sobre aconselhamento (no que se refere às concepções de subjetividade e às recomendaçôes aos profissionais de saúde para execução de seu trabalho) e análise de entrevistas realizadas com aconselhadores atuando em CTA. Foram produzidos três artigos referentes a essas análises e submetidos à avaliação de revistas científicas (dois deles já no prelo). Neste trabalho, esses três artigos serão acionados para contribuir com as reflexões propostas, não sendo, portanto, aprofundados nas questôes teóricas e metodológicas que os embasam. 
Cabe esclarecer que o caminho reflexivo adotado no presente artigo parte

de um plano analítico de problematização e debate das questões em foco, para então assumir um caráter propositivo quanto à formação de aconselhadores em HIV/Aids. As proposições para a formação são dirigidas à prática específica do aconselhamento, não sendo extensivas ao debate sobre a formação em cursos de graduação. As indicações apresentadas estão implicadas com o desafio de se construir respostas efetivas e eficazes à Aids. O aconselhamento como dispositivo está envolvido na desafiante tarefa de barrar a cadeia de transmissão do HIV, em especial nas situações de risco de infecção por exposição sexual. Juntamente com insumos disponíveis no SUS (preservativos, profilaxia pósexposição), o aconselhamento é dispositivo imprescindível no enfrentamento da disseminação do HIV.

Pesquisa sobre mudanças na testagem anti-HIV com amostra representativa do Brasil urbano, escutando homens e mulheres de 16 a 65 anos de idade, identificou que, em 2005, metade das pessoas testadas disseram não ter recebido aconselhamento pré-teste ou pós-teste (FRANÇA JÚNIOR; CALAZANS; ZUCHI, 2008, p. 95). Esse dado é bastante preocupante, já que a associação entre testagem e aconselhamento

[...] propicia reflexão sobre os riscos de infecção e a necessidade de sua prevenção por meio de mudanças comportamentais. Estima-se que novas infecções poderiam ser reduzidas em $30 \%$ ao ano caso todas as pessoas infectadas soubessem sua sorologia para o HIV.

Em relato sobre a experiência na construção de políticas públicas em DST/ Aids no Estado de São Paulo, Gonçalves e Pupo (2003) destacam como fator alarmante na realidade encontrada a falta de preparo de profissionais de saúde para o trabalho com prevenção e aconselhamento, já que a maioria deles não havia passado por treinamento específico para atuação nesses campos. Além disso, era comum a esses profissionais citarem mídias populares (TV, rádio, revistas) como fontes de informação sobre DST/Aids, indicando ausência de fundamentos consistentes para a atuação neste campo.

A formação de profissionais para a área de saúde tem sido problematizada em pesquisas. Em estudo etnográfico acompanhando médicos que assistiam a pessoas vivendo com HIV e/ou Aids, Santos (2009, p. 98) associa as dificuldades desses profissionais em prestar atenção mais humanizada à própria formação. "O aprendizado de ser médico relega a segundo plano os aspectos subjetivos do 
processo de adoecimento". O treinamento médico é voltado para a doença e em como curá-la, não oferecendo subsídios para o atendimento à pessoa e para a escuta de aspectos subjetivos do paciente. Assim, a prática desses profissionais fica restrita à intervenção técnica, segundo a hegemônica herança biomédica desse campo de saber.

Quanto à formação para atuação em saúde pública Ferreira Neto (2008, p. 143) destaca o descompasso entre a capacidade de empregabilidade do SUS, desde sua fundação, e o desenho pedagógico das graduações na área de saúde: “[e] stas permanecem reféns de uma tradição de atenção individual, do trabalho profissional isolado, da prevalência de um ensino técnico e, na maior parte das áreas, biomédico". Nesse sentido, as açōes de cuidado no SUS carecem de maior articulação entre teoria e prática, além de uma necessária ampliação da atenção individual para coletiva, perspectiva que embasa a lógica do sistema. No campo específico da formação em Psicologia, por exemplo, a dissociação entre psicologia clínica e psicologia social comunica ao formando uma separação artificial de aspectos da vida humana (FERREIRA NETO, 2004).

Pensar a formação de profissionais de saúde para a prática do aconselhamento em HIV/Aids, portanto, constitui tarefa importante no sentido de qualificar esse tipo de cuidado, que é estratégico para uma resposta mais efetiva à Aids.

\section{O aconselhamento no campo do trabalho em saúde}

Aprendemos com Karl Marx (1985) que é na produção social de suas vidas que os humanos vivem relações de produção correspondentes a determinada etapa do desenvolvimento de suas forças produtivas materiais. Os estudos de Marx identificaram a sociedade vigente - a que temos até hoje - como capitalista e seu modo de propriedade correspondente, o privado. O pensamento de Karl Marx, bem como o de seus sucessores e críticos, tem inspirado muitas produções sobre a questão do trabalho nas sociedades capitalistas. Grande parte delas tem sido dirigida à produção industrial de bens materiais.

De acordo com Traverso-Yépez (2008, p. 69), “o setor serviços de saúde tende a funcionar com igual lógica de mercado que o setor de produção". Concorre para esse quadro a associação entre as racionalidades científica e econômica, cuja valorização do modelo biomédico é expoente. A questão é que esse modelo, a partir do uso de tecnologias médicas, prioriza o controle e prevenção de doenças, 
deixando "de lado as condições sociais de vida e a subjetividade da pessoa que sofre” (p. 72), reduzindo assim a saúde a um tipo de mercadoria.

Análise de manuais do MS sobre concepções de subjetividade na prática do aconselhamento em HIV/Aids (GALINDO; FRANCISCO; RIOS, no prelo[a]) indica que a subjetividade dos usuários é concebida como uma identidade, cuja definição é baseada nas práticas sexuais. A subjetividade-identidade com a qual lidam os manuais reduz os usuários a marcas valorativas inscritas no campo discursivo em torno da Aids. Ganham destaque nos manuais referências a homossexuais, mulheres, gestantes, pessoas com diagnóstico de tuberculose, cuja associação com situações de risco é direta. Assim, usuários são identificados a grupos e/ou comportamentos considerados de risco, associação dos primeiros tempos da Aids, cuja efetividade tem sido questionada no quadro de respostas à epidemia (SOUZA; CZERESNIA, 2007; AYRES et al., 2003; PARKER, 2000).

A concepção de subjetividade-identidade engendra saberes, orienta práticas não comprometidas com a promoção da saúde e agenciamento de ações de cuidados. Ao contrário, reduzir os sujeitos a uma identidade como uma marca da qual não se escapa, parece estar a serviço do controle da população, controle dos corpos que o Estado de governo agencia como biopolítica, reproduzindo tendência histórica nas sociedades ocidentais (RIOS; PARKER; TERTO JÚNIOR, 2010; SPINK, 2010; FOUCAULT, 2007; CALIMAN, 2006).

A ideia da saúde como um tipo de mercadoria pode estar orientando a dinâmica que engendra os modos de trabalho no campo do aconselhamento em HIV/Aids. Recomendações do MS a aconselhadores em HIV/Aids, conforme análises realizadas na pesquisa de doutorado da primeira autora, são sugestivas da postura mecânica e reprodutora esperadas desse profissional. De acordo com os manuais (BRASIL, 1999, 1998, 1993), o aconselhador é agente ativo na cena do aconselhamento, diante do usuário que passivamente recebe orientações. As recomendações são marcadas pela racionalidade instrumental típica da organização capitalista do trabalho (VASCONCELOS, 2007), isto é, quase como um circuito do tipo de produção industrial em que o aconselhamento é caracterizado pela emissão de informações do profissional (input) ao usuário que, ao processá-las, poderá gerar mudanças de comportamento (output).

Além disso, as recomendaçôes assumem caráter diretivo, prescritivo, como se o encontro com o usuário fosse previsível e burocratizável. Nas recomendações 
não são aprofundados debates sobre como intervir, negligenciando assim os aspectos singulares dos usuários e do encontro. Também tomam essa direção as recomendações para formação de aconselhadores, indicadoras de concepção simplista e reducionista da complexa tarefa do profissional de saúde e da dinâmica de sua relação com o usuário. Nesse sentido, portanto, identificou-se nas recomendações do MS que os aconselhadores não participam efetivamente das ações interventivas na rotina do CTA nem da construção do programa de formação. Ao contrário, os trabalhadores da saúde parecem reduzidos a executores de procedimentos, a exemplo do que ocorre na produção material (industrial). Assim, um componente de alienação, de não-saber, já bastante discutido ao se abordar a lógica capitalista de produção material (MARX, 1984), parece estar presente também na prática do aconselhamento.

O não-saber implícito na produção material constitui um dos mais significativos antagonismos do capitalismo. Caracteriza-se pelo alheamento do trabalhador ao todo do processo produtivo, reduzindo seu conhecimento à ação que executa em uma pequena parte da cadeia de produção. Ao mesmo tempo em que o trabalhador participa da produção de algo que seria incapaz de fazer sozinho, ele desconhece os detalhes do processo dessa produção. Não-saber, ao mesmo tempo em que garante o distanciamento dos operários de reflexóes aprofundadas sobre as relaçóes de trabalho no capitalismo, possibilita a manutenção da linha de produção. Por isso, alterações nesse quadro - em benefício da conscientização dos operários quanto aos processos dos quais participa - não se conseguem apenas pela compreensão racional dos antagonismos presentes no processo de trabalho, conforme têm investido muitas iniciativas da chamada esquerda, no campo da política (ŽIŽEK, 1996; 1992). De acordo com esse autor, é no campo das práticas que se deve investir para que os operários tenham acesso, criticamente, à dinâmica das relações de trabalho e seus antagonismos. Conforme indicam os estudos de Žižek (1992), os trabalhadores podem até saber, isto é, ter uma compreensão racional do que fazem (um trabalho mecânico, fragmentado do todo, com remuneração aquém dos lucros que gera), mas continuam fazendo (executando ações mecânicas pontuais que garantem o funcionamento da linha de produção). $\mathrm{O}$ argumento de Žižek (1996, 19922) é que o modo como os operários engendram suas atividades laborais, isto é, a forma que suas práticas assumem, tem mais possibilidade de proporcionar transformações significativas no processo de conscientização. 
Conforme já referido, o aconselhamento como modalidade de trabalho em saúde é de ordem não-material (MERHY, 2007), diferente, portanto, do trabalho de produção industrial (material). Ao mesmo tempo, o aconselhamento tende a funcionar com a mesma lógica de mercado que o setor produtivo, posto que na sociedade capitalista a saúde éconsiderada como uma mercadoria (TRAVERSOYÉPEZ, 2008).

Um componente de não-saber, portanto, parece estar na base das recomendações do MS sobre a prática do aconselhamento, já que não abordar os fundamentos das orientações, bem como não explicitar o como fazer, reduz o trabalho dos profissionais de saúde ao cumprimento de procedimentos mecânicos, burocráticos. Não-saber sobre seu próprio trabalho parece garantir sua execução de forma acrítica, repetindo um fazer padronizado, previsível. Essa norma termina por garantir interesses do Estado de governo no controle das populações (usuários em atendimento) e dos trabalhadores de saúde, enrijecidos em procedimentos que impedem a criação de práticas de cuidado que priorizem o usuário.

Explicitar racionalmente esse quadro aos trabalhadores da saúde - como recurso para alterar possíveis práticas reprodutoras de um trabalho mecânico e aproximá-las de perspectiva complexa de ações no campo da saúde - não é suficiente para promover alterações na prática dos trabalhadores (ŽIŽEK, 1992). Investimentos no campo da prática, portanto, merecem ser feitos, no sentido de uma formação de profissionais que estejam implicados com a complexidade do trabalho que executam. Nessa perspectiva, apresentaremos proposições para a formação de aconselhadores em HIV/Aids.

Pesquisa empírica com aconselhadores atuando em CTA de Pernambuco (GALINDO; FRANCISCO; RIOS, no prelo[b]) confirma a tendência em reduzir o aconselhamento a uma prática protocolar. Chamamos de aconselhamentoinstrução o modo de aconselhar que enfatize o caráter informativo além de concentrar saber e poder na figura do profissional de saúde. No aconselhamentoinstrução, que tem status de modalidade hegemônica na pesquisa realizada, o usuário é considerado responsável por sua condição sorológica, inclusive pela redução de índices de infecção pelo HIV, associada à mudança de seu comportamento. Os profissionais de saúde, nesse tipo de prática, são agentes do biopoder, isto é, põem em ato, no encontro com o usuário, as recomendações do MS de educar, orientar, adotando postura de vigilância de comportamentos. 
Nesta mesma pesquisa identificamos, ainda que de forma tênue, um modo de aconselhar a que chamamos aconselhamento-relação. $\mathrm{O}$ usuário é considerado em sua singularidade, sendo rejeitadas quaisquer noções de individualização, interiorização que poderiam remeter à compreensão de uma identidade. ${ }^{1}$ No aconselhamento-relação, o usuário tem participação ativa; é respeitado em suas próprias construções em torno dos temas abordados, o que direciona o encontro com o profissional, não havendo um protocolo que oriente previamente o trabalho do aconselhador. Este tem como tarefa primordial escutar, acolher, facilitar processo reflexivo por parte do usuário, no sentido de que ele possa fazer deslocamentos, rearranjos nos modos como organiza sua vida e sua relação com as questôes em foco, sempre na perspectiva de promoção da saúde.

As ferramentas de trabalho do aconselhador, nessa modalidade, assemelhamse ao que Merhy (2007, p. 49) nomeia de "tecnologias de relações, de encontros de subjetividades, [que estão] para além dos saberes tecnológicos estruturados, comportando um grau de liberdade significativo na escolha do modo de fazer essa produção" não material, que é o aconselhamento. O autor chama esse tipo de tecnologia de leve, diferenciando-a das leves-duras (saberes estruturados) e duras (equipamentos, máquinas).

Identificamos, ainda, no aconselhamento-relação, o que Merhy (2009) chama de encontro de intercessão partilhada, caracterizado pela troca, diálogo entre trabalhador e usuário. Esse tipo de encontro favorece a expressão de linhas de fuga, isto é, de movimentos instituintes em relação ao modelo instituído envolvido. Por isso, o espaço intercessor ${ }^{2}$ possibilita que o trabalho em saúde seja do tipo "vivo em ato", cabendo aos profissionais de saúde (e gestores) compreender o que tal espaço está comunicando quanto à atenção dispensada à população. É desde o encontro com o usuário, portanto, que o profissional de saúde poderá desenvolver mudanças em sua prática, dispensando à população o cuidado devido, tentando assim escapar da tônica mercadológica na saúde.

A partir da pesquisa realizada, defendemos que o aconselhamento seja tratado como um dispositivo e não meramente como uma técnica de trabalho no campo de saúde. Um dispositivo é constituído por vários aspectos, dentre os quais leis, discursos, regulamentações, enunciados científicos, referências morais, organizaçōes arquitetônicas, aspectos filosóficos (FOUCAULT, 2007). Como dispositivo, o aconselhamento em HIV/Aids parece estar organizado em 
torno de questôes que envolvem o diagnóstico do HIV, com vistas ao controle da

epidemia de Aids. À primeira vista, é uma interessante perspectiva no quadro de respostas à Aids. Entretanto, quando aprofundamos a compreensão da dinâmica que assume os diversos elementos implicados no aconselhamento, temos que a vigilância e o controle da população aparecem como estratégia; os sujeitos que buscam o aconselhamento são reduzidos a concepções associadas a suas práticas sexuais como norteadoras do que são e como se comportam; a relação profissional de saúde-usuário assume a tendência de ser diretiva e prescritiva. O dispositivo do aconselhamento, nesse sentido, está a serviço do controle dos corpos.

Defendemos que o dispositivo do aconselhamento esteja implicado com a emancipação de sujeitos e coletividades no campo da saúde. A própria pesquisa nos dá pistas de como assumirmos essa direção do aconselhamento. Trata-se das expressões identificadas nas análises, como potência: da subjetividade-cidadã para se considerar o sujeito do aconselhamento (e não a subjetividade-identidade); do aconselhamento relação, como modo de aconselhar (e não o aconselhamento instrução). É nessa direção, portanto, que traçamos proposições para a formação de profissionais nesse campo.

\section{Proposições para formação de aconselhadores}

Se, por um lado, constata-se que o trabalho em saúde é do tipo não material, isto é, "é feito e consumido" no momento mesmo em que acontece; por outro lado, a ainda hegemônica ideologia biomédica na área reflete uma racionalidade econômica e tecnológica a serviço, prioritariamente, de interesses do capital, e da manutenção dos antagonismos do capitalismo, mesmo que isso não seja tão explícito.

Debate interessante sobre formação de profissionais de saúde foi feito por Ceccim e Feurwerker (2004), ao proporem que a formação seja pautada no quadrilátero ensino, gestão, atenção e controle social. A articulação desses quatro vetores, presentes na realidade do trabalho em saúde, deveria ser objeto de atenção nos cursos de formação em saúde. De acordo com os autores, as instituições formadoras têm repetido um modelo conservador em suas práticas.

A atualização técnico-científica é apenas um dos aspectos da qualificação das práticas e não seu foco central. A formação engloba aspectos de produção de subjetividade, produção de habilidades técnicas e de pensamento e o adequado conhecimento do SUS. A formação para a área da saúde deveria ter como objetivos a transformação das práticas profissionais e da própria organização do trabalho, e estruturar-se a partir 
da problematização do processo de trabalho e sua capacidade de dar acolhimento e cuidado às várias dimensões e necessidades de saúde das pessoas, dos coletivos e das populações. (CECCIM; FEUERWERKER, 2004, p. 43).

Medeiros (2010, p. 501-502), ao dialogar com o artigo de Ceccim e Feurwerker (2004), propõe que cada elemento do quadrilátero seja considerado como organizador de um tipo de discurso. Argumenta a favor de que o eixo nomeado de Controle Social seja chamado de Usuário, pelo caráter de cidadania que é atribuído àquela dimensão. Essa torção na produção original é inspirada no trabalho de Jacques Lacan, que "procurou formalizar, através da dialética hegeliana, do marxismo, da matemática e da lógica moderna, um estudo sobre as possibilidades de subversão aos discursos vigentes, o que viria a chamar de discurso analítico". Para Medeiros, o dispositivo criado por Lacan possibilitou a análise do discurso analítico, a partir da construção de um sistema em que se articulam os discursos do mestre, da universidade, do analista e da histeria. ${ }^{3}$

Ainda que as contribuições de Medeiros (2010, p. 511) sejam consideradas por ele como em processo de elaboração já que indicam continuidade de seus estudos, vale à pena destacar a hipótese de trabalho do autor, de que talvez seja "mais rico para a pesquisa e adequado à realidade, considerar o elemento chamado de usuário como o sujeito [...], ou seja, o que excede e provoca a subversão em determinado discurso dominante". Consideramos que esse posicionamento é semelhante ao defendido por Merhy (2009), de que é no encontro com o usuário que se tem acesso ao instituinte, isto é, ao que pode escapar e/ou subverter uma dada ordem.

Para o trabalhador em saúde, atuar nesse campo é mobilizador de inquietações. De acordo com as reflexōes apresentadas, para evitar sua sujeição à lógica do nãosaber e, enfim, desenvolver seu trabalho na direção de que o usuário seja sujeito do processo de atenção à saúde, parece sensato considerar que o trabalhador deve assumir posicionamento crítico diante do contexto no qual desenvolve suas atividades. Assim, poderá construir criativamente fazeres cujo impacto extrapola uma intervenção meramente técnica, mobilizando nos usuários em atendimento, nos colegas de trabalho, na rotina da unidade de saúde, processos que podem ser capazes de engendrar novos modos de ser e de agir distintos daqueles comprometidos com a manutenção dos discursos vigentes. O campo, por excelência, onde essas mudanças são possíveis, é o do encontro com o usuário. 
Apresentamos princípios e conteúdos que possam subsidiar a formação de aconselhadores em HIV/Aids, seja por mobilizar reflexôes em aconselhadores já atuando na função, seja orientando o desenho pedagógico de capacitações de profissionais que ainda iniciarão seu trabalho nesse campo. São pistas que podem ser aprofundadas em estudos subsequentes.

\section{Princípios para a formação}

Habilidades para conduzir um aconselhamento em HIV/Aids merecem ser desenvolvidas a partir da compreensão/estudo das diversas dimensões implicadas nessa prática. Consideramos habilidades, nesse contexto, a integração de aspectos objetivos (informações sobre possibilidades de infecção, formas de prevenção, história da epidemia da Aids, perfil epidemiológico atual) e subjetivos (dúvidas, inquietações, fantasias do usuário em torno dos temas em questão, bem como modos de expressão da sexualidade, de obtenção de prazer sexual, de arranjos afetivo-sexuais que vivencia - enfim, de como lidar com os aspectos em foco) na prática profissional.

A compreensão/estudo das dimensões implicadas no cuidado ao usuário, referida acima, envolve investimentos racionais e afetivos do profissional em formação. A mera transmissão de informações ao profissional de saúde em formação, sobre os temas em questão, é insuficiente para um aprendizado que possibilite uma abordagem humanizada do usuário. Os processos de formação precisam mobilizar os profissionais a se engajarem no aprofundamento dos conteúdos, mas ao mesmo tempo merecem tratar essa tarefa com cuidado para que a forma que assumirem nas relações no processo formativo seja de fortalecimento da autonomia do profissional e de princípios democráticos. Alguns cuidados merecem ser tomados pelo/a facilitador/a da formação, como o uso de linguagem simples e acessível, evitando-se a utilização de jargões específicos de determinado campo de saber e a valorização da experiência já acumulada dos profissionais em formação, já que o conhecimento não está concentrado no facilitador, mas circulando no processo. É imprescindível também garantir abertura para que os profissionais se expressem, o que certamente contribuirá para abordagem de valores, concepções - isto é, referências pessoais sobre os temas em foco, permitindo que o facilitador problematize os assuntos abordados. Outro recurso 
nessa direção é ilustrar os trabalhos com casos clínicos de aconselhamento (reais ou fictícios), provocando os formandos para refletirem sobre a situação apresentada, o que fortalece a perspectiva do aconselhamento como campo aberto no qual o profissional precisa ajustar sua prática às questões trazidas pelo usuário. Essa direção, portanto, afasta a ideia de que o aconselhamento tenha um roteiro protocolar previamente definido.

As diversas dimensóes implicadas no aconselhamento, apresentadas explícita ou implicitamente pelo usuário, no momento do atendimento, podem ser de ordem pessoal, social, institucional, dentre outras. Aspectos ligados à vida mais íntima do usuário, relacionados à motivação para buscar o aconselhamento, às concepções, valores, fantasias em torno dos temas em questão e aspectos da própria vivência da sexualidade, precisam ser tratados com cuidado e atenção. Como o usuário apresenta, no aconselhamento, aspectos implicados com dinâmicas sociais mais amplas, como religião, política, economia. Quanto às questões institucionais, é importante ter sensibilidade para aquelas relacionadas ao percurso do usuário até o momento do aconselhamento. Como chega ao aconselhamento - se por demanda espontânea, se vem por encaminhamento de outra unidade de saúde pode ter significados diferentes para o próprio usuário. Nesta dimensão também estão envolvidos os elementos que já compõem a relação do usuário com a unidade de saúde, antes mesmo de chegar ao aconselhamento, como acolhida na recepção, tempo de espera para ser atendido e demais aspectos do fluxo de rotina do serviço.

As dimensóes implicadas no aconselhamento, ainda que tenham um recorte pessoal, a partir da história de cada usuário, podem ser aprofundadas pela equipe de aconselhadores, em reuniōes de estudo. A realidade local do município, bairro, ou comunidade que busca o aconselhamento pode ser estudada com a especificidade necessária. Faz-se imprescindível não generalizar conhecimentos de uma realidade para todas, sob o risco de incorrer em violência simbólica, isto é, na imposição de uma compreensão da realidade sem considerar as particularidades de cada situação. No caso de um curso de capacitação, pode ser feito um exercício, convidando os formandos a identificarem, por exemplo, especificidades culturais (de determinada localidade) em relação aos temas em questão (uso do preservativo, arranjos afetivo-sexuais).

Para as equipes que já têm uma prática, é importante garantir momentos nos quais sejam realizados estudos temáticos, estudos de caso e ajustes de 
procedimentos, para dar um caráter processual à formação, evitando a ideia de que ela é pontual e esgota-se após a conclusão de um curso/encontro formal. Nos encontros de equipe podem ser estudadas as situaçôes vivenciadas na unidade de saúde, de modo que o emergente do aconselhamento - isto é, o que é da ordem do instituinte, perceptível diante de um encontro do tipo partilhado seja valorizado como indicador do tipo de relação construída entre profissional e usuário e entre unidade de saúde e usuário, a partir do que podem ser feito ajustes na perspectiva de qualificar o trabalho.

\section{Conteúdos para a formação}

Os conteúdos a serem trabalhados na formação devem estar em segundo plano em relação à forma que assumem os processos formativos, mas não devem ser considerados inferiores por isso. Como os conteúdos embasam concepções e práticas, é importante permitir sua expressão o mais livremente possível; assim será possível problematizar, junto com os profissionais de saúde em formação, pensamentos e sentimentos. Cuidados com a forma que assume o processo formativo podem contribuir para a espontânea expressão do que pensam, sentem, acreditam e rejeitam os próprios profissionais, o que é material de atenção na formação. Assim, defendemos que os conteúdos não falem por si - isto é, não se bastem para que um profissional de saúde se torne aconselhador; sua experiência ao abordar os conteúdos é que produz significativas aprendizagens. Sugerimos, portanto, que a abordagem dos conteúdos afaste-se de uma apresentação objetiva, uma explanação, e seja trabalhada em processos participativos nos quais os aconselhadores em formação sejam convocados a serem protagonistas de suas aprendizagens.

Com esse desafio, elencamos alguns conteúdos importantes para compor o processo formativo, mas alertamos que a dinâmica história da epidemia de Aids e a resposta que temos construído para ela merece ser considerada criticamente, já que pode nos indicar novos temas a serem considerados nas formações de aconselhadoras.

Sobre a infecção pelo HIV, vários conteúdos merecem atenção- dentre eles, as formas de se contrair o vírus (de mãe para filho; pelo sangue; pelo sexo) e a diferença entre o HIV (vírus) e Aids (doença), com destaque para a importância de diagnóstico precoce para convivência com o HIV/Aids. Nesse debate é importante trabalhar a mensagem de que o HIV é um ser vivo e, no 
corpo humano, ele encontra alimento no sistema imunológico. Ainda no quadro de questôes em torno da infecção, merecem ser incluídas informações sobre a assistência a pessoas soropositivas, inclusive a necessidade de exames para avaliar a necessidade de medicação antirretroviral. Esses conteúdos possibilitam o diálogo com questões emblemáticas no campo do HIV/Aids, que muitas vezes aprisionam as pessoas em atitudes e comportamentos que pouco auxiliam nos cuidados com a saúde. Trata-se, por exemplo, da ideia de que HIV e Aids são a mesma coisa; a equivocada referência de que sintomas como perda de peso e queda de cabelo são sinais da presença de Aids no organismo; a expectativa de iniciar medicação logo que se recebe um resultado soropositivo para HIV. Enfim, o bloco de questões em torno de infecção merece dedicar atenção cuidadosa aos diversos aspectos que podem estar arranjados de tal modo, equivocadamente, que comprometem o cuidado das pessoas para com sua saúde.

As políticas públicas no campo do HIV/Aids constituem um segundo bloco de questôes a serem consideradas na formação. A articulação da resposta à Aids com princípios e diretrizes do Sistema Único de Saúde (SUS), inclusive com o reconhecimento de que aquela resposta inspirou, em muito, o desenho do SUS, é conteúdo imprescindível a ser abordado. O estudo sobre como prevenção e assistência estão associados na resposta brasileira à Aids, desde os seus primórdios, e como se expressam na realidade atual é outra questão importante. Como os equipamentos CTA, SAE, PSF têm lidado com o enfrentamento da Aids, inclusive com reflexões sobre o desenho que vem tomando essa estrutura nos municípios nos quais os aconselhadores em formação atuam, pode se constituir em estratégia interessante de mobilização para que os profissionais de saúde se engajam politicamente na construção das políticas locais de Aids.

Além da história da estruturação política dos governos para responder à Aids, merece atenção a história social da epidemia no Brasil, em especial, as construções discursivas que, na nossa história, associaram o risco de infeção a grupos específicos, socialmente já marcados por estigmas e exclusões, como homossexuais, prostitutas, usuários de drogas. Tocar nessas questões pode ser estratégico para o estudo sobre mudanças no perfil epidemiológico da Aids, tanto em nível nacional, quanto nas realidades locais dos profissionais em formação, o que poderá mobilizá-los a elaborarem ações específicas para determinados grupos que figurem mais vulneráveis à infecção. Nesse bloco de questões, é possível 
avançar no estudo de temas como preconceitos e tabus e o desfio de lidar com eles no atendimento à população.

Um capítulo sobre subjetividade é importante existir num programa de formação de aconselhadores. $\mathrm{O}$ estudo de que concepções de subjetividade são marcadas por uma construção social, histórica e geográfica contribuirá para a reflexão crítica sobre a sexualidade como referência principal para se saber sobre o sujeito. A abordagem desses conteúdos convida para o debate sobre singularidades e diversidade sexual, temas que possibilitam o manejo mais produtivo da subjetividade no aconselhamento.

As tecnologias envolvidas no trabalho do aconselhamento são outro tópico imprescindível na formação das aconselhadoras. Os profissionais precisam saber sobre os diversos tipos de exames anti-HIV existentes e a interpretação dos resultados, além do que será utilizado na rotina da unidade em que trabalha. Essas informações poderão contribuir no diálogo com o usuário, caso este demande esclarecimentos dessa ordem. A valorização de tecnologias leves no trabalho com o usuário, como escuta, olhar, atenção, acolhida, diálogo, vínculo, contribuirá para qualificar a atenção dispensada à população. Além disso, o estudo sobre tipos de relação trabalhador da saúde-usuário - objetal e partilhada - pode ser extremamente profícuo para autocrítica, revisão de posturas, ajustes na rotina, enfim, para adoção de uma perspectiva crítica no trabalho.

Finalmente, questôes em torno da organização do trabalho na unidade de serviço de saúde, são fundamentais no processo de formação. Os desafios e estratégias para o trabalho em equipe multidisciplinar e a abordagem de tensões e conflitos comuns em qualquer ambiente de trabalho contribuirão para que os aconselhadores aprimorem suas habilidades no trato com colegas, chefias, usuários. A acolhida ao usuário como tarefa de toda equipe e não só de aconselhadores é um importante elemento a ser considerado também.

As proposições apresentadas merecem tratamento específico pelo planejamento de oficinas de formação, objeto de atenção de publicaçōes posteriores, pela continuidade da pesquisa.

\section{Considerações finais}

Problematizar o processo de formação de aconselhadores a partir das reflexões apresentadas teve como objetivo contribuir para a qualificação da prática do 
aconselhamento. Tal como a realidade tem nos mostrado, apenas transmitir informações à população sobre os riscos de se contrair o HIV não tem sido suficiente para barrar a cadeia de transmissão do vírus (BRASIL, 2012; PARKER, 2000). Entendemos que o trabalho de formação de profissionais também deve escapar de postura diretiva, prescritiva.

A abordagem de temas tão delicados como os associados à Aids (práticas sexuais, riscos à saúde e os carregados de preconceito como culpa, vergonha, morte) merece o devido respeito às singularidades no encontro com o usuário. Não cabe ao aconselhador julgar, avaliar, normatizar os diversos modos de ser e estar no mundo, mas acolher o usuário para que ele seja protagonista de sua saúde, da direção de suas rotinas e práticas de cuidados de si.

De acordo com as proposições apresentadas, o profissional em formação tem a oportunidade de identificar, explicitar, problematizar, ajustar suas próprias ideias, sentimentos, valores sobre os temas em foco. É a subjetividade do aconselhador que ganha destaque como elemento a ser considerado, respeitado, com o qual deve dialogar o processo de formação. Apostamos que relações horizontalizadas do facilitador com os profissionais em formação propiciam experiência importante do aconselhador em ser acolhido, escutado. Acredita-se que tal vivência possibilite ao profissional em formação, posicionamento dialógico junto ao usuário.

As reflexões e proposições apresentadas neste artigo tentam dar conta da tarefa de elaborar sugestōes para a formação de aconselhadores em HIV/Aids a partir de análises dos manuais do MS e de entrevistas com aconselhadores atuando em CTA, meta da pesquisa de tese. As proposiçôes dialogam com algumas produçôes e experiências disponíveis na literatura científica sobre o dispositivo do aconselhamento e/ou ações de cuidado no campo da saúde. Neste artigo não foram trabalhadas tais articulações, mas entendemos que merecem ser pontuadas como interlocuçóes imprescindíveis na continuidade dos estudos - o planejamento de oficinas de formação.

Nesse sentido, é importante levar em conta as diversas produções científicas em torno da questão, em especial as que indicam a necessidade de investimentos na formação médica para o aprendizado da formação de vínculos pessoais entre profissionais e usuários (SANTOS, 2009); as que defendem a identificação de analisadores institucionais, o que pode provocar mudanças no jogo de 
forças presentes na dinâmica institucional na qual se dá o trabalho em saúde (FERREIRA NETO, 2008).

É indispensável levar em conta a perspectiva de emancipação psicossocial como norteadora de práticas comprometidas em politizar o campo de trabalho em HIV-Aids. "Quando esse tipo de espaço psicoeducativo acontece em programas de prevenção do HIV e da Aids [...] incentiva a busca conjunta de outros espaços solidários e soluções fora do escopo dos projetos e programas" (PAIVA, 2002, p. 36). Além disso, as práticas de saúde implicadas com um Cuidado efetivo, "no qual a presença do outro seja ativa e as interaçōes intersubjetivas sejam ricas e dinâmicas" são importantes balizadoras das açōes (AYRES, 2009, p. 70).

Vale à pena ter presente, na continuidade do desenvolvimento dos estudos, o recurso do diálogo problematizador (de acordo com a pedagogia de Paulo Freire) como norteador da prática do aconselhamento (MIRANDA et al., 2008). Também apoiadas nas contribuições de Paulo Freire, Santorum e Cestari (2011, p. 237) defendem a educação popular como orientadora da formação de profissionais de saúde, com argumento de que "é preciso que se assuma explicitamente a politicidade da formação para a saúde". Em artigo que analisam curso de extensão universitária voltado para o SUS, consideram a educação popular como uma "prática na qual se assume que estamos a favor do povo, contra todas as formas de injustiça e desigualdade, e não a favor da alienação e da manutenção das situações desumanas em que vive grande parte da população”.

A importância de estreitar laços entre diversos atores como governos, organizações não governamentais, instituições acadêmicas, movimentos sociais para formação de recursos humanos, definição de políticas e reflexão crítica contínua de ações no campo da Aids também é um importante aspecto a ser considerado (CAMARGO JÚNIOR, 2003).

Não é demais lembrar que modos de viver, bem como modos de intervir tendem a ser marcados por referenciais engendrados nas tramas do complexo sistema capitalista. Nunca é demais pontuar que é possível escapar de determinações que massificam, padronizam e traçar linhas de fuga que indiquem novas direções para a existência. Nessa perspectiva, espera-se do profissional de saúde-aconselhador habilidades para produzir criativamente ações indicadoras de que seu trabalho é implicado com a superação de quadros de preconceitos, desigualdades, dominação, 
valores, enfim, que sustentam o (ainda não superado) desafio de barrar a cadeia de transmissão do HIV. Nesse sentido, associamos a prática do aconselhamento ao definido por Fonseca e Farina (2012) como clinicar:

Clinicar é colocar-se eticamente na produção do mundo e da vida como obra de arte e em uma dimensão eminentemente social. A clínica é, portanto, destrutiva das representaçôes pretensamente universais que aprisionam a subjetividade numa história individual e pessoal, descolada das produçôes político-sociais. Arte e clínica se encontram na tarefa de criticar o presente e produzir a vida por vir (p. 50).

Esperamos, com este artigo, contribuir para o debate sobre formação de aconselhadores e, por conseguinte, qualificar a resposta à Aids. ${ }^{4}$

\section{Referências}

AYRES, J.R.C.M. Cuidado: trabalho e interação nas práticas de saúde. Rio de Janeiro: Cepesc, 2009.

AYRES, J.R.C.M. et al. Conceito de vulnerabilidade e as práticas de saúde: novas perspectivas e desafios. In: CZERESNIA, D.; FREITAS, C.M. (Orgs.). Promoção da saúde: conceitos, reflexôes, tendências. Rio de Janeiro: Fiocruz, 2003. p.117-139.

BRASIL. Ministério da Saúde. Boletim Epidemiológico Aids e DST. Brasília, ano VIII, n. 1, 2012. - Ministério da Saúde. Aconselhamento em DST, HIV e Aids: diretrizes e procedimentos básicos. 3a ed. Brasília: MS, 1998.

. Ministério da Saúde. Diretrizes dos Centros de Testagem e Aconselhamento - CTA: manual. Brasília: MS, 1999.

- Ministério da Saúde. Normas de organização e funcionamento dos Centros de Orientação e Apoio Sorológico. Brasília: MS, 1993.

. Ministério da Saúde. Secretaria de Vigilância em Saúde. Programa Nacional de DST e Aids. Oficina de aconselhamento em DST/HIVIAIDS para Atenção Básica. Brasília: MS, 2005.

CALIMAN, L.V. Dominando corpos, conduzindo ações: genealogias do biopoder em Foucault. In: JACÓ-VILELA, A. M., CEREZZO, A.C.; RODRIGUES, H.B.C. (Orgs.). Clio-Psyché: subjetividade e história. Juiz de Fora: Clio, 2006.

CAMARGO JÚNIOR, K.R. Prevenções de HIV/Aids: desafios múltiplos. Dialogando em Saúde para Debate, n. 27, p. 70-80, ago 2003.

CECCIM, R.B.; FEUERWERKER, L.C.M. O quadrilátero da formação para a área da saúde: ensino, gestão, atenção e controle social. Physis: Revista de Saúde Coletiva, v. 14, n. 1, p. 41- 65, 2004.

FERREIRA NETO, J. A formação do psicólogo: clínica social e mercado. São Paulo: Escuta, 2004. 
. Intervenção psicossocial em saúde e formação do psicólogo. Psicologia \& Sociedade,

v. 20, n. 1, jan-abr, 62-69, 2008.

FONSECA, T.M.G.; FARINA, J.T. Clinicar. In: FONSECA, T.M.G. et al. (Orgs.). Pesquisar na diferença: um abecedário. Porto Alegre: Sulina, 2012.

FOUCAULT, M. Governabilidade. In: Microfísica do Poder. Rio de Janeiro: Graal, 2007.

FRANÇA JÚNIOR, I.; CALAZANS, G.; ZUCHI, E.M. Mudanças no âmbito da testagem anti-HIV no Brasil entre 1998 e 2005. Rev Saúde Pública, v. 42, supl. 1, p. 84-97, 2008.

GALINDO, W.C.M.; FRANCISCO, A.L.; RIOS, L.F. Subjetividade no aconselhamento em HIV/Aids. Revista Psicologia Política, no prelo[a].

. A instrução e a relação como modos de aconselhamento em HIV/Aids. Revista Temas em Psicologia, no prelo[b].

GONÇALVES, D.A.; PUPO, L.R. Articulação institucional na prevenção das DST/Aids: desafios na implementação de políticas públicas para populações excluídas. In: BOCK, A.M.B. (Org.). Psicologia e Compromisso Social. São Paulo: Cortez, 2003.

MARX, K. O Capital: crítica da economia política. 9a ed. São Paulo: Difel, 1984.

. Para uma crítica da economia política (Prefácio). In: ABRIL CULTURAL. Os Pensadores. São Paulo: Abril, 1985.

MEDEIROS, R.H. A. A construção de um dispositivo que permita estudar os discursos que organizam o campo da saúde: um ensaio sobre os efeitos discursivos e a formação do profissional em saúde. Physis: Revista de Saúde Coletiva. Rio de Janeiro, v. 20, n. 2, p. 497-514, 2010.

MERHY, E.E. Enfrentar a lógica do processo de trabalho em saúde: um ensaio sobre a micropolítica do trabalho vivo em ato, no cuidado. In: CARVALHO, S.R.; FERIGATO, S.; BARROS, M.E. (Orgs.) Conexôes Saúde Coletiva e Politicas de Subjetividade. São Paulo: Hucitec, 2009, p. 276-300.

Saúde: a cartografia do trabalho vivo. 3a ed. São Paulo: Hucitec, 2007.

MIRANDA, K.C.L. et al. Reflexões sobre o aconselhamento em HIV/AidsS em uma perspectiva freireana. Rev Bras Enferm, v. 61, n. 6 p. 889-903, nov-dez 2008.

PAIVA, V. Sem mágicas soluções: a prevenção e o cuidado em HIV/Aids e o processo de emancipação psicossocial. Interface: Comunic, Saúde, Educ. Botucatu, v. 6, n. 11, p. 2538, 2002.

PARKER, R. Na contramão da Aids: sexualidade, intervenção, política. Rio de Janeiro: Abia, 2000.

PIRES, D. Reestruturação produtiva e trabalho em saúde no Brasil. 2a ed. São Paulo: Annablume, 2008. 
RIOS, L.F., PARKER, R.; TERTO JUNIOR, V. Sobre as inclinações carnais: inflexôes. Do pensamento cristão sobre os desejos e as sensações prazerosas do baixo corporal. Physis: Revista de Saúde Coletiva. Rio de Janeiro, v. 20, n. 1, p. 2010, 195-217.

SANTORUM, J.A.; CESTARI, M.E. A Educação popular na práxis da formação para o SUS. Trab. Educ. Saúde, v. 9, n. 2, p. 223-240, jul./out., 2011.

SANTOS, D.F. HIV/Aids e os médicos em formação: aprendendo a cuidar de vírus ou pessoas? In: CAMARGO JRr., K.R.; NOGUEIRA, M.I. Por uma filosofia empírica da atenção à saúde: olhares sobre o campo biomédico. Rio de Janeiro: Fiocruz, 2009.

SOUZA, V.; CZERESNIA, D. Considerações sobre os discursos do aconselhamento nos centros de testagem anti-HIV. Interface: Comunic, Saúde, Educ. Botucatu, v. 11, n. 23, p. 531-48, 2007.

SPINK, M. J. Psicologia Social e Saúde: trabalhando com a complexidade. Quaderns de Psicologia, v. 12, n. 1, p. 41-56, 2010.

TRAVERSO-YÉPEZ, M. A Psicologia Social e o Trabalho em Saúde. Natal: UFRN, 2008.

VASCONCELOS, E.M. Abordagens Psicossociais. V. 1: História, Teoria e Trabalho no campo. São Paulo: Hucitec, 2008.

ŽIŽEK, S. Como Marx inventou o sintoma? In: . (org.). Um Mapa da Ideologia.

Rio de Janeiro: Contraponto, 1996.

. Eles não sabem o que fazem: o sublime Objeto da Ideologia. Rio de Janeiro: Jorge Zahar, 1992.

\section{Notas}

${ }^{1}$ Essa modalidade de aconselhamento sugere articulações com a concepção de subjetividade-cidadã, identificada na análise dos manuais como alternativa sutil à hegemônica subjetividade-identidade (GALINDO; FRANCISCO; RIOS, no prelo[a]).

${ }^{2} \mathrm{O}$ autor apoia suas reflexôes no conceito de intercessor, de G. Deleuze.

${ }^{3}$ Para aprofundar a análise que o autor faz dos discursos no campo da saúde por analogia aos discursos estudados por J. Lacan, conferir o artigo de referência.

${ }^{4}$ W.C.M. Galindo realizou pesquisa bibliográfica, sistematização e análise de material; foi responsável pela redação do texto e participou de debates sobre ajustes necessários, efetivando mudanças. A.L. Francisco participou das discussões que subsidiaram a elaboração do texto, contribuindo com sugestôes bibliográficas e ajustes na redação. L.F. Rios participou das discussões que subsidiaram a elaboração do texto, contribuindo com sugestôes bibliográficas e ajustes na redação. 
Proposals for training counselors on HIV/AIDS Ths paper discusses the formation of counselors in HIV / AIDS, requirement of the Ministry of Health for health professionals to develop this practice among users seeking HIV testing. To addressing training is strategic to qualify their practice, building more efficient and effective responses to AIDS. Analyses of manuals of the ministry and interviews with advisors, conducted within a research thesis (in progress), subsidize the discussion. From the analyses of textbooks are highlighted the concept of subjectivity-identity, as a relentless brand defined by the user's sexual practices, and prescriptive and directive trend in recommendations for professionals. From the analysis of interviews, we highlight the identified advising ways - education and respect. These findings add to the reflections on the advice - treated as health device and non material production in the context of reflections on the world of labor in capitalist societies. It is suggested that counseling tends to be captured by the commodity perspective, the close association between scientific and economic rationality in the health field. This arrangement is supported by the still hegemonic ideology in biomedical health practices. To escape this direction, it is suggested critical positioning for counselors in conducting their work, avoiding directive and protocol posture. The counseling-relationship is presented as an alternative advisory way by using lightweight technologies, aligned relationships, respect for differences and the role of the user in his own care. Finally, propositions (principles and contents) are presented to conduct training processes towards relationship-advice.

> Key words: counseling; health staff; health education. 